\title{
The International Mathematical Union (IMU) at 100
}

\section{Carlos E. Kenig}

The main objectives of the IMU are to promote international cooperation in mathematics and to encourage and support international activities that contribute to the development of the mathematical sciences in all their aspects-pure, applied, or educational. In addition, the IMU determines the location and the scientific program of the International Congress of Mathematicians (ICM) and acknowledges outstanding research contributions to mathematics by awarding scientific prizes. Although many mathematicians think of the IMU strictly in terms of its connection with the ICM, this article highlights a more comprehensive view of the programs and activities that come under its purview. In particular, the IMU is deeply involved in initiatives that support mathematics and mathematics education in the developing world, and in worldwide efforts aimed at achieving gender balance and equality for underrepresented groups in the sciences.

\section{A Snapshot of the Work of the IMU Today}

A precursor of the current IMU was founded in Strasbourg, France, in 1920. Thus the year 2020 brings the centenary celebration of the IMU. The original incarnation of the IMU was dissolved in 1932. After the disruption caused by World War II, at a convention in New York in 1950, the current version of the IMU was created based on the principle of unrestricted internationalism, namely, "mathematics without borders." In 1950, the ICMs also resumed, every four years. For an in-depth history of the IMU and the ICMs, see Mathematics without borders, a history of the International Mathematical Union by O. Lehto, Springer 1998 and Mathematicians of the world unite! The International Congress of

Carlos E. Kenig is a professor of mathematics at the University of Chicago and president of the International Mathematical Union, 2019-2022. His email address is cek@math.uchicago.edu.

For permission to reprint this article, please contact: reprint-permission aams.org.

DOI: https://dx.doi.org/10.1090/noti2050
Mathematicians - A Human Endeavor by G. Curbera, Taylor and Francis 2009. ${ }^{1}$

Today, the work of the IMU is very complex, involving a number of components, which take the form of commissions and committees. The IMU has eighty-nine member countries and organizes activities all over the world. This structure has been greatly facilitated by the creation of a permanent Secretariat for the IMU, in the heart of Berlin, Germany. The Secretariat was established in 2011 on a trial basis, and made permanent in 2019, thanks to the generous support of the German Government and the State of Berlin. The Secretariat runs the IMU's day-to-day business and provides administrative support for many IMU operations. The IMU Secretary General heads the work of the IMU Secretariat. The IMU's archive is housed in the Secretariat, ensuring its preservation for posterity.

The IMU is administered by an Executive Committee (EC), which conducts the business of the union, assisted by the IMU Secretariat. The EC is responsible for all policy matters and for tasks such as choosing the members of various committees of the IMU. The members of the IMU are countries, represented through an Adhering Organization. The dues paid by the Adhering Organizations finance the bulk of the activities of the IMU. Every four years, the IMU members gather in a General Assembly (held just before the ICM). The major decisions of the IMU are made at the General Assembly, by vote.

\section{The Work of the Commissions and Committees of the IMU}

\subsection{International Commission on} Mathematical Instruction (ICMI) https: //www. mathunion.org/icmi

The IMU keeps in close contact with mathematics education through the ICMI, the oldest Commission in the IMU.

${ }_{1}$ Both books are freely available from https://www.mathunion.org /organization/imu-history 
The ICMI was established in 1908 at the International Congress of Mathematicians in Rome and thus precedes the IMU. The founding President of the ICMI was the German mathematician Felix Klein. After interruptions of activity around the two world wars, the ICMI was reconstituted in 1952 and then became an official Commission of the IMU. The ICMI offers a forum to disseminate ideas related to the teaching and learning of mathematics, from the primary to the tertiary level. An important objective of the ICMI is to connect mathematics educators, teachers of mathematics, mathematicians, educational researchers, curriculum designers, and others interested in mathematical education at all levels, around the world, to improve the teaching of mathematics. Thus, the ICMI deals with the full spectrum of mathematics education, from theoretical research in mathematics education to the practice of mathematical education, for all ages.

The ICMI's activities cover three main series of conferences organized on a regular basis. They are the Studies Conferences (the Studies are conducted by an international team of leading scholars and practitioners, to address topics of particular significance in contemporary mathematical education; more than twenty Studies volumes have been published); the Regional Conferences, taking place in regions all over the world; and the International Congress on Mathematical Education, a major responsibility for the ICMI, which is held every four years, and whose attendance and impact in the mathematical education community are comparable to the ICMs in the mathematical community (see https://www. icme14.org).

The ICMI recognizes outstanding achievements in mathematics education research through two biannual prizes, the Felix Klein Award (for lifetime achievement) and the Hans Freudenthal Award (for a major cumulative program of research). The ICMI recognizes outstanding achievements in the practice of mathematics education through the quadrennial Emma Castelnuovo Award.

The ICMI and the IMU cooperate on a number of projects. One of them, the Klein Project, was inspired by Klein's book Elementary Mathematics from an Advanced Standpoint. It is dedicated to supporting mathematics teachers as they connect the mathematics they teach to contemporary research in the mathematical sciences. The associated blog (plog.kleinproject.org) includes short articles styled as "vignettes" on interesting applications of mathematics such as "How Google works: Markov chains and eigenvalues" and "What is the way of packing oranges? Kepler's conjecture on the packing of spheres."

\subsection{Commission for Developing Countries (CDC)}

https: //www . mathunion.org/cdc

The activities of the IMU in developing countries are run by the CDC, created in 2010. The CDC and its partners manage to have a very high impact with very limited resources. Among the important programs that the CDC runs are graduate scholarships, grants for mathematicians to lecture and mentor in developing countries, and educational and local capacity building programs. For instance, the IMU Breakout Graduate Fellowship Program, ${ }^{2}$ which is run by the CDC through generous and ongoing donations by winners of the Breakthrough Prizes in Mathematics, is a fellowship program to support excellent students in developing countries to carry out postgraduate studies leading to a PhD degree in the mathematical sciences. The Graduate Assistantships in Developing Countries program provides funds for graduate research assistantships to the most talented graduate students in emerging research groups working in a developing country. The research group has to have an ongoing collaboration with an international mathematician working in a different country, who then acts as a partner in the training of the students. The CDC also provides partial support for mathematicians to attend conferences in the mathematical sciences organized in developing countries. In a few cases, international conferences in developed countries are supported by the CDC in order to invite mathematicians from developing countries.

The CDC manages a Volunteer Lecturer Program for developing countries. The program offers universities in developing countries the economic support to host volunteer lecturers for intensive 3-4 week courses in mathematics. The course given by the volunteer is part of a regular undergraduate or master's degree program at the host institution. The CDC maintains a database of volunteer lecturers, who then get matched to requests. The program is partially funded by the AMS and the Niels Henrik Abel Board, the entity that oversees Norway's funds for the Abel Prize. The Abel Visiting Scholar Program (supported by the Abel Board) supports mathematicians professionally based in developing countries to visit an international collaborator for a period of one month. The IMU-Simons African Fellowship Program, supported by the Simons Foundation, supports sabbaticals for mathematicians from African developing countries to travel to an internationally known mathematical center of excellence for collaborative research.

The CDC partners with the ICMI on the Capacity and Networking Project to develop the educational capacity of those responsible for the education of mathematics teachers in regions of the developing world. This project is in response to UNESCO's 2011 Current Challenges in Basic Mathematics Education. Since this project reaches teachers at all levels (from elementary schools onwards) this program has great transformative potential. The Capacity and Networking Project workshops have been held in the Francophone Sub-Saharan Region, in Central America and

${ }^{2}$ For further information on the CDC and the Breakout Graduate Fellowships, see the recent Notices article by Della Dumbaugh, https:// www.ams.org/journa1s/notices/201908/rnoti-p1294.pdf and the editorial in IMU-Net 93: January 2019 by Terence Tao and Richard Taylor. 
the Caribbean, in Southeast Asia, and in the Andean Region of South America and Paraguay.

\subsection{International Commission for} the History of Mathematics (ICHM) https://www. mathunion.org/ichm

The ICHM is an inter-union commission, joining the IMU and the Division of the History of Science of the International Union for the History and Philosophy of Science and Technology. The aim of the ICHM is to encourage the study of the history of mathematics and to promote a high level of historically and mathematically sophisticated scholarship in the field. The IMU appoints two representatives as members of the ICHM Executive Committee. The ICHM sponsors and/or cosponsors symposia at the International Congresses of the History of Science and of Mathematics, and celebrates excellence in the history of mathematics through the awarding of the Kenneth O. May Medal and the Montucla Prize.

\subsection{Committee on Electronic Information and Communication (CEIC) \\ https://www. mathunion.org/ceic}

The CEIC is a standing committee of the Executive Committee. Its mandate is to advise the EC on matters concerning information and communication. This includes advising on standards and best practices for mathematical journals and on issues pertaining to electronic publishing and open access. The CEIC endorses and advises the EC regarding the Digital Mathematics Library, the project to make the entirety of past mathematics scholarship available online, at a reasonable cost, in a digital collection, developed and curated by a network of institutions.

\subsection{Committee for Women in Mathematics (CWM) https://www . mathunion.org/cwm}

In 2015, the EC approved the creation of the CWM, to promote international contacts between national and regional organizations for women and mathematics. The CWM has been extraordinarily active and successful, putting forward a number of initiatives and always supporting the ideal of gender equality in the mathematical sciences. The CWM helps establish and foster networks of women mathematicians in Asia, Latin America, and Africa. The CWM also supports schools for women mathematicians, especially in the developing world. In 2018, the CWM organized the $(\mathrm{WM})^{2}$ World Meeting for Women in Mathematics as a satellite meeting of ICM2018 in Rio de Janeiro, Brazil, the day before the inauguration of ICM2018. A CWM tribute to Maryam Mirzakhani (1977-2017, Fields Medalist in 2014) was inaugurated at (WM) $)^{2}$ and remained open during ICM2018. It is expected that the next edition of (WM) ${ }^{2}$ will take place in Saint Petersburg, Russia, on July 5, 2022, the day before the inauguration of ICM2022.

The IMU, through the CWM, was chosen by the International Science Council to be one of two lead partners in its funded project "A Global Approach to the Gender Gap in Mathematical, Computing and Natural Sciences: How to Measure It, How to Reduce It?" The final meeting of the project took place in November 2019 at the International Center for Theoretical Physics in Trieste, Italy. A report on the project, as well as the tools produced to carry out the project and its recommendations, were unveiled at this meeting.

\section{The International Congress of Mathematicians and the IMU Awards}

\subsection{International Congress of Mathematicians (ICM)} Although the IMU today does much more than sponsoring an International Congress of Mathematicians, the ICM remains the flagship activity of the IMU. The next ICM will be held on July 6-14, 2022 in Saint Petersburg, Russia (https://icm2022.org).

The ICM is widely regarded as the premier international gathering of mathematicians. Meeting every four years, the Congress plays a unique role in mathematics, both by recognizing exemplary recent research achievements in all the various subfields of mathematics and by giving the broader community of mathematicians the opportunity to learn about the latest mathematical research developments and to interact with leaders in the field. This latter aspect of the Congress is particularly valuable for early career mathematicians and for mathematicians from developing countries who might otherwise have only limited ways to interact with such leaders. The IMU is responsible for the scientific program of the Congress. All other organizational tasks are the domain of the host country. Up to 2018, the entire scientific program of the Congress, from the choice and size of its sections, to the selection of individual speakers, was the responsibility of the Program Committee (PC).

\subsection{New developments at the ICM}

The tightness of the PC's schedule and its large mandate made it very difficult for the PC to be able to make substantial changes to the scientific structure of the Congress. Over time there has been growing concern that the division of mathematics into sections has evolved very slowly. Moreover, it is generally recognized that the Congress caters more to the "pure" subdisciplines of mathematics rather than to the "applied" ones. Since, in principle, the ICM offers a uniquely promising opportunity for pure and applied mathematicians to come together and learn about the latest exciting developments at the interface between these two mathematical disciplines, and since there are currently so many exciting developments in novel applications of mathematics, it is time for a change. With this background, the 2018 General Assembly approved the formation of a new committee, the Structure Committee (SC), whose membership is chosen by the EC and whose charge is to decide the scientific structure of the Congress, thus relieving the PC of 
this part of its enormous task. The full membership of the SC is publicly known and available at the IMU's website. In contrast, only the chair of the PC is known. The remaining members will be revealed at ICM2022. The SC is to remain a standing committee (with rotating membership), charged with continuously evaluating and revising the scientific structure of the Congress, to keep it constantly current.

\subsection{The IMU awards}

The IMU awards the following prizes for mathematical achievement every four years at the Opening Ceremony of the ICM.

Fields Medal: This award recognizes outstanding mathematical achievement for existing work, and for the promise of future achievement, by mathematicians under forty years of age. Two to four awards are made at each ICM. It was first awarded in 1936.

Rolf Nevanlinna Prize: This award recognizes outstanding contributions to the mathematical aspects of information science. It was first awarded in 1982. The prize was discontinued by vote of the General Assembly in 2018, to be replaced from now on by the IMU Abacus Medal, with identical statutes.

Carl Friedrich Gauss Prize: This award recognizes outstanding mathematical contributions that have found significant applications outside of mathematics. It is awarded jointly by the IMU and the Deutsche MathematikerVereinigung (DMV). It was first awarded in 2006.

Chern Medal Award: This award celebrates an individual whose accomplishments warrant the highest recognition for outstanding achievements in the field of mathematics. It is awarded jointly by the IMU and the Chern Medal Foundation. It was first awarded in 2010.

The Leelavati Prize is awarded at the Closing Ceremony of the ICM every four years and recognizes outstanding public outreach work for mathematics. It was first awarded in 2010, and since 2014 it has been sponsored by Infosys.

The IMU recognizes the work of women who have made fundamental and sustained contributions to the mathematical sciences through a special ICM plenary lecture, the ICM Emmy Noether Lecture.

The IMU Executive Committee appoints, for each of its awards, a Selection Committee. Only the names of the chairs of the committees are made public before the ICM. Nominations, observing the specific prize statutes, are encouraged. They should be sent to the chair of the relevant committee. For the names and addresses of the chairs, please consult the IMU's website, https://WWW . mathunion.org.

\section{Final Remarks}

The IMU website contains extensive information about the activities of the organization. The IMU also publishes an electronic bimonthly newsletter, the IMU-Net. You can subscribe to it by sending an email to imu-net-request amathunion.org with the subject line: subscribe.

The International Mathematical Union is involved in a whole host of activities that promote international cooperation in mathematics. These activities range from support for the research and practice of mathematics education, to helping unleash the full potential of the developing world in the mathematical sciences, to supporting the elimination of the gender gap in the sciences. The Committee on Electronic Information and Communication helps the international mathematical community navigate the transition in publishing brought on by electronic forms of communication and supports the Digital Mathematics Library project, which is a great aspiration of the world's mathematical community. The IMU continues to provide the most determined support for research in the mathematical sciences in many ways with its International Congresses of Mathematicians and associated awards.

All of this would be impossible without the tireless work of many volunteers from the worldwide mathematical community. Please give your help to this enterprise by joining these volunteers! The IMU is funded through the dues paid by the Adhering Organizations and through generous donations. Some of these contributions are large, like the ones from the German Government and the State of Berlin, which fund the Secretariat, and the ones from the Breakthrough Prize winners, which fund the IMU Graduate Breakout Fellowship Program to support graduate studies in developing countries. Some are small, like the ones AMS members make $(\$ 8)$ when they tick a box in their AMS membership renewal form. Small or large, these donations add up to support a fully functioning IMU. Please consider supporting the IMU and its programs as we begin our next century of work together.

ACKNOWLEDGMENTS. The author thanks the two anonymous referees for their very careful reading of the first version of this article and for their many excellent detailed suggestions and comments that have greatly improved the presentation. The author would also like to thank Helge Holden, Secretary General of the IMU, for his helpful comments on the first draft of this article.

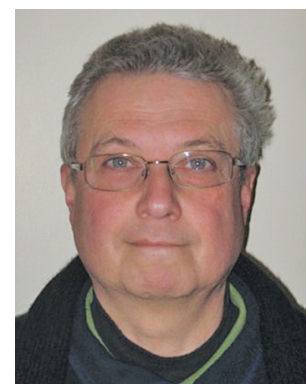

Credits

Author photo is by Sarah Ziesler. 